\title{
Commentary
}

\section{Front-of-pack nutrition labelling in the European region: identifying what works for governments and consumers}

\author{
Bridget Kelly ${ }^{1, *}$ and Jo Jewell ${ }^{2}$ \\ ${ }^{1}$ Early Start, University of Wollongong, Northfields Avenue, Wollongong, NSW 2522, Australia: ${ }^{2}$ World Health \\ Organization Regional Office for Europe, Copenhagen, Denmark
}

Submitted 29 October 2018: Final revision received 20 November 2018: Accepted 26 November 2018: First published online 15 January 2019

\begin{abstract}
Objective: The present commentary introduces a Health Evidence Network (HEN) report that synthesises evidence of front-of-pack food labelling (FOPL) policy development and implementation across the European Region.

Design: Countries were identified as having policies on interpretive FOPL from the WHO databases of Member State policies and online repositories of global food policies. For each identified country, evidence published from 1 January 1980 to 31 March 2018 was retrieved from peer-reviewed and grey literature. Extracted data were cross-checked with in-country representatives to ensure completeness and accuracy. Setting: WHO European Region, spanning fifty-three countries.

Results: Fifteen countries had a government-endorsed policy on interpretive FOPL. Thirteen of these countries had introduced endorsement logos, while only three labelling systems provided an indicator for unhealthfulness. Common steps were identified in FOPL policy development, including: establishing FOPL as a nutrition policy priority; engaging stakeholders and the public; and collecting formative evidence on which to base the labelling system. Few countries had outlined formal provisions for evaluation of FOPL systems. The HEN report describes seven considerations for the adoption/review of FOPL policies to ensure these achieve the population nutrition aims of FOPL. These considerations relate to supporting consumer use and understanding of the labelling, policy feasibility and credibility, and ensuring policy implementation and accountability.

Conclusions: The HEN report encourages countries to consider FOPL policy that is applied widely across all products and provides negative evaluative judgements, possibly combined with positive indicators. Implementation provisions should drive widespread uptake of the system and allow for formal evaluation of impact.
\end{abstract}

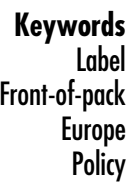

Evidence indicates that over one-quarter of all foods purchased by households across Europe are highly processed. Countries with the highest household availability of highly processed foods also have the highest rates of adult obesity $^{(1)}$. Audits of retail store environments generally indicate that shelf space devoted to processed foods high in saturated (and trans) fatty acids, sugar and/or salt often exceeds that for healthier foods ${ }^{(2,3)}$. This retail food environment, where less healthy foods dominate and consumer choice is distorted by marketing claims and point-of-purchase promotions, is unsupportive in assisting shoppers to select healthier products. Nutrition labelling provides an important tool to support consumers to make healthier food choices and may also drive food product reformulation. Nutrition labels that are presented on the front of food packages and that use interpretational aides, such as interpretative words, colours and symbols, are more likely to be used and understood by consumers ${ }^{(4-9)}$. Consequently, the WHO European Food and Nutrition Action Plan 2015-2020 identifies the introduction of interpretative, consumer-friendly labelling on the front of packages as a priority policy issue ${ }^{(10)}$.

To support countries in the WHO European Region to implement front-of-pack labelling (FOPL) aligned with the Food and Nutrition Action Plan, the Health Evidence Network (HEN) recently compiled an evidence synthesis on the development and implementation of interpretive front-of-pack nutrition labelling policies across the WHO 
European Region ${ }^{(11)}$. HEN is an information service for public health system decision makers, initiated and coordinated by the WHO Regional Office for Europe. HEN reports synthesise the best available evidence to respond to policy questions and propose concrete, actionable policy options. The primary intention of the report was to highlight good practice examples of FOPL policy development and implementation and inspire countries to continue working actively on food policies to promote healthy diets. For the purpose of that report, nutrition information was considered to be FOPL if it was typically displayed in the principal field of vision ${ }^{(12)}$ and if the intention of the label was to guide healthier food choices. This included nutrient-related warning labels and endorsement logos.

Fifteen countries in the WHO European Region were identified as having a government-endorsed policy on interpretive FOPL. A limited range of FOPL systems were identified to be in use across Europe that provided an indicator for unhealthfulness. These included the NutriScore system in France, the red warning label in Israel and the colour-coded percentage Reference Intake (\%RI) system in the UK. The communication of product unhealthfulness is likely a critical element in the performance of FOPL in supporting better food choices. Consumer research has identified that purchase decisions are more often based more on negative evaluative judgements than on positive judgements, and that negative judgements reduce impulsivity towards less healthful foods ${ }^{(13,14)}$. Inclusion of direct indicators of product unhealthfulness therefore reduces the potential for overinterpreting the healthfulness of labelled products. In the remaining thirteen countries, endorsement logos have been adopted. These logos serve to signpost better-for-you choices but provide no direct information to indicate if a product is unhealthful. This focus on identifying the healthiest options without flagging less healthy products is a limitation of endorsement logos that potentially undermines their potential to meet population nutrition aims. Specifically, consumers may misunderstand endorsement logos to represent healthier choices overall ${ }^{(15)}$, overinterpreting these to infer that a product is 'good', and thereby lead to overconsumption of labelled foods in less healthful categories $^{(16)}$.

The HEN report also identified common steps involved in FOPL policy development. This included establishing FOPL as a nutrition policy priority, engaging stakeholders and the public, and collecting formative evidence on which to base the labelling system. There was a wide divergence between countries in the extent to which they had conducted formative research and consumer testing during the development of the FOPL. In all but one country (Israel), FOPL policies were implemented under voluntary arrangements, with variable penetration of the labels into the marketplace. Voluntary implementation is at least partly a result of existing European Union regulations that prevent national governments from implementing mandatory national FOPL systems ${ }^{(17)}$. However, the voluntary nature of most schemes means that uptake across the food supply is generally less than optimal and highly variable between countries.

As part of FOPL system implementation, few countries with FOPL policies had outlined formal provisions for evaluation of new FOPL systems. Monitoring and evaluation are recognised as a key element in policy implementation more broadly, to understand the impact of the action and to guide future activities or improvements ${ }^{(18)}$. Despite the paucity of available detail on provisions for FOPL policy evaluation, published studies were available on the effect of the identified FOPL systems on consumer label use and understanding, and food choice, purchase and intake. Most published information on FOPL performance related to proximal impacts of label implementation, including label understanding, and relatively less on longer-term dietary and health outcomes. Studies assessing the effect of endorsement logos on food choice found these to have limited impact on influencing the healthfulness of selected foods. A small number of identified studies that assessed the impact of the Nutri-Score system and traffic light coloured FOPL find that these systems better support the selection of more nutritionally favourable products. Less information was available on the effect of FOPL on actual food purchases. Improvements to the nutritional quality of purchased foods have been found with the Nutri-Score system but not for traffic light colour-coded labels. The evaluation evidence presented was limited to studies that assessed FOPL systems identified as being implemented in the European countries with FOPL policies. However, the findings were broadly aligned with other published review articles, which similarly identify a slew of information towards more proximal outcomes of label implementation including label understanding and relatively less information on dietary and health outcomes.

Based on the evidence synthesised in the HEN report, a number of considerations were identified for the adoption or review of FOPL policies at the national or regional level to ensure policies achieve the population nutrition aims of FOPL. These include:

1. establishing a single, consistent FOPL system to aid consumer use and understanding of the label;

2. utilising a system of interpretive FOPL that can provide evaluative judgements about product unhealthfulness, which appears to be a more effective way to support consumers to choose nutritionally favourable products it may also highlight better for-you choices, thus providing both positive and negative evaluative judgements;

3. reflecting upon the possibility that endorsement logos alone could encourage consumers to overestimate the healthfulness of products and engender a price 
premium, which may have implications for low socioeconomic groups;

4. opting for government-led policy development rather than a commercially based system as consumers perceive the latter as less credible;

5. developing the scope of FOPL policies based on stakeholder engagement and formative research to ensure that the right policy is chosen for the population;

6. exploring ways to overcome issues with uptake of the labelling system in the marketplace, including through mandatory implementation;

7. supporting implementation through the development of guidance documents for industry to facilitate label adoption and public education initiatives to stimulate consumer demand for the labels and improve awareness and understanding; and

8. creating a formal and comprehensive policy monitoring and evaluation programme to assess implementation and impact (e.g. outcomes such as knowledge, attitudes and behaviour, purchasing and consumption changes, reformulation, and potential health effects).

Poor diet is the leading cause of mortality and morbidity across the WHO European Region, including contributing to obesity, type 2 diabetes mellitus, CVD and some types of cancer. Nutrition labelling is one of the policy tools that can be leveraged to support healthy diets. When this labelling is readily noticeable, understood and compelling, it has the potential to stimulate consumers to make healthier food choices and to drive reformulation of products where manufacturers seek to avoid making unfavourable nutrient content disclosures. Such labelling must be complemented by other aligned policy actions that improve economic and physical access to healthy foods, increase the desirability of healthy choices, and reduce the normalisation and promotion of unhealthy choices. The extent that FOPL will improve population food choices depends, at least partly, on consumers' ability to understand the information presented and their motivation to apply it. Based on the evidence reviewed, the HEN report encourages countries to consider an FOPL system that is applied widely across all products and provides negative evaluative judgements, possibly combined with positive indicators as well. Implementation provisions should drive widespread uptake of the system and allow for formal evaluation of impact.

\section{Acknowledgements}

Acknowledgements: The authors thank to the Health Evidence Network (HEN) editorial team at the WHO Regional Office for Europe for commissioning and supporting the preparation of the HEN report on front-of-pack food labelling policies in the WHO European Region. Financial support: The HEN report on front-of-pack food labelling policies in the WHO European Region was funded by the WHO Regional Office for Europe. Conflict of interest: J.J. is a staff member of the WHO Regional Office for Europe. The authors are responsible for the views expressed in this publication, which do not necessarily represent the decisions or stated policy of WHO. Authorship: B.K. and J.J. co-wrote the manuscript. Ethics of buman subject participation: Not applicable.

\section{References}

1. Monteiro CA, Moubarac J-C, Levy RB et al. (2018) Household availability of ultra-processed foods and obesity in nineteen European countries. Public Health Nutr 21, 18-26.

2. Vandevijvere S, Mackenzie T \& Mhurchu CN (2017) Indicators of the relative availability of healthy versus unhealthy foods in supermarkets: a validation study. Int J Behav Nutr Phys Act 14, 53.

3. Cameron A, Thornton L, McNaughton SA et al. (2013) Variation in supermarket exposure to energy-dense snack foods by socio-economic position. Public Health Nutr 16, $1178-1185$.

4. van Kleef E \& Dagevos H (2015) The growing role of frontof-pack nutrition profile labeling: a consumer perspective on key issues and controversies. Crit Rev Food Sci Nutr 55 , 291-303.

5. Grunert KG \& Wills JM (2007) A review of European research on consumer response to nutrition information on food labels. J Public Health 15, 385-399.

6. Cecchini M \& Warin L (2016) Impact of food labelling systems on food choices and eating behaviours: a systematic review and meta-analysis of randomized studies. Obes Rev 17, 201-210.

7. Hersey JC, Wohlgenant KC, Arsenault JE et al. (2013) Effects of front-of-package and shelf nutrition labeling systems on consumers. Nutr Rev 71, 1-14.

8. Storcksdieck genannt Bonsmann S \& Wills JM (2012) Nutrition labeling to prevent obesity: reviewing the evidence from Europe. Curr Obes Rep 1, 134-140.

9. Talati Z, Pettigrew S, Neal B et al. (2017) Consumers' responses to health claims in the context of other on-pack nutrition information: a systematic review. Nutr Rev $\mathbf{7 5}$, 260-273.

10. World Health Organization Regional Office for Europe (2014) European Food and Nutrition Action Plan 20152020. http://www.euro.who.int/_data/assets/pdf_file/ 0008/253727/64wd14e_FoodNutAP_140426.pdf (accessed October 2018).

11. Kelly B \& Jewell J (2018) What is the Evidence on the Policy Specifications, Development Processes and Effectiveness of Existing Front-of-Pack Food Labelling Policies in the WHO European Region? Health Evidence Network (HEN) Synthesis Report no. 61. Copenhagen: WHO Regional Office for Europe; available at http://www.euro.who.int/_data/ assets/pdf_file/0007/384460/Web-WHO-HEN-Report-61-onFOPL.pdf

12. Storcksdieck genannt Bonsmann S, Celemín LF, Larrañaga A et al. (2010) Penetration of nutrition information on food labels across the EU-27 plus Turkey. Eur J Clin Nutr 64, 1379-1385.

13. Scarborough P, Matthews A, Eyles H et al. (2015) Reds are more important than greens: how UK supermarket shoppers use the different information on a traffic light nutrition label in a choice experiment. Int J Behav Nutr Phys Act 12, 151. 
14. Rohr M, Kamm F, Koenigstorfer J et al. (2015) The color red supports avoidance reactions to unhealthy food. Exp Psychol 62, 335-345.

15. Norstat (2015) Landsrepresentativ undersøkelse vedrørende det norske folks kjennskap, kunnskap og holdning til Nøkkelhullet. https://helsedirektoratet.no/Documents/Kosthold\% 20og\%20ern\%C3\%A6ring/Forbrukerunders\%C3\%B8kelse_n\% C3\%B8kkelhullet_2011-2015.pdf (accessed May 2018).

16. Kleef EV \& Dagevos H (2015) The growing role of front-ofpack nutrition profile labeling: a consumer perspective on key issues and controversies. Crit Rev Food Sci Nutr $\mathbf{5 5}$, 291-303.

17. European Commission (2011) Regulation (EU) No 1169/ 2011 of the European Parliament and of the Council on the provision of food information to consumers. https:// eur-lex.europa.eu/legal-content/EN/TXT/PDF/?uri=CELEX: 32011R1169\&from=EN (accessed December 2018)

18. World Health Organization (2006) Global Strategy on Diet, Physical Activity and Health. A Framework to Monitor and Evaluate Implementation. Geneva: WHO. 